\title{
Inadequacies in the habitual nutrient intakes of patients with metabolic syndrome: a cross-sectional study
}

\author{
Aline Tuane Oliveira da Cunha ${ }^{1}$, Hermilla Torres Pereira' ${ }^{1}$, Sephora Louyse Silva de Aquino², \\ Cristiane Hermes Sales ${ }^{3}$, Karine Cavalcanti Maurício Sena-Evangelista ${ }^{4}$, Josivan Gomes Lima ${ }^{{ }^{*}}$, \\ Severina Carla Vieira Cunha Lima ${ }^{4}$ and Lucia Fatima Campos Pedrosa ${ }^{4}$
}

\begin{abstract}
Background: Dietary factors are important environmental factors associated with the prevalence of metabolic syndrome (MS). The objective of this study was to assess the habitual nutrient intakes of patients with MS.

Methods: A cross-sectional study included 103 patients (82 \% women) with MS seen at the endocrinology outpatient clinic of Hospital Universitario Onofre Lopes. Habitual nutrient intake data were collected at two 24-h dietary recalls. Macronutrient intake adequacies were classified according to the I Brazilian guidelines for the diagnosis and treatment of metabolic syndrome. The prevalence of inadequate micronutrient intake was estimated using the estimated average requirements (EAR) cut-point method after adjusting for intra- and interpersonal variances and energy.

Results: The mean energy intake of the included patients was $1523.0 \pm 592.2 \mathrm{kcal} / \mathrm{d}$, higher in men (1884.0 vs. $1441.5 \mathrm{kcal} / \mathrm{d}$ in women; $p=0.003)$. The recommended percentage protein intake was exceeded in both women and men (18\% in women and $19 \%$ in men). Although men consumed more fiber (18.8 vs. $13.3 \mathrm{~g} / \mathrm{d}$ in women; $p=0.011)$, their intake was still inadequate. Women consumed more fat (47.6 vs. $41.3 \mathrm{~g} / \mathrm{d}$ in men; $p=0.007$ ). The prevalence of inadequate vitamin D and calcium intakes exceeded $80 \%$ in both men and women and across all age groups. The same was observed for magnesium in men and women aged more than 30 years. The prevalence of inadequate vitamin $\mathrm{E}$, riboflavin, and zinc intakes in men ranged from 50 to $75 \%$. The prevalence of inadequate vitamin $\mathrm{A}$, vitamin C, thiamin, vitamin B6, copper, and selenium intakes in men and women was less than $50 \%$.
\end{abstract}

Conclusions: Patients with MS had high protein intake, low fiber intake, and high a prevalence of inadequate vitamin D, magnesium, and calcium intakes.

Keywords: Metabolic syndrome, Food intake, Nutrients, Nutritional requirements, EAR

\section{Background}

Metabolic syndrome (MS) is a complex disorder represented by a set of cardiovascular risk factors that include hyperglycemia, hypertriglyceridemia, low levels of highdensity lipoprotein cholesterol (HDL-c), elevated waist circumference, and high blood pressure [1].

\footnotetext{
*Correspondence: josivanlima@gmail.com

${ }^{5}$ Departamento de Medicina Clínica, Universidade Federal do Rio Grande do Norte, Av. Nilo Peçanha, 620, Petrópolis, Natal, RN CEP: 59010-180, Brazil

Full list of author information is available at the end of the article
}

The global prevalence of MS in adults ranges from 20 to $25 \%$ [2], and in Brazil, from 4.9 to $65.3 \%$, including urban and rural areas and indigenous populations [3]. The prevalence of MS in adults aged 20-59 years was $4.5 \%$ and increased with age, from $1.3 \%$ in adults aged $20-29$ years to $5.6 \%$ in those aged $30-39$ years and $26.3 \%$ in those aged $\geq 40$ years [ 4 .

MS has a multifactorial etiology that depends on interactions between metabolic, genetic, and environmental factors. Among the environmental factors, diet is one of the main risk factors associated with the increased 
prevalence of MS [5]. Dietary intervention is an important strategy for the prevention and control of MS [6].

In recent years, the effects of isolated foods and dietary patterns have been investigated in the development of MS [7-10]. Dietary patterns consisting of high consumption of red and/or processed meat, refined grains, and fried foods are directly associated with an increased risk of MS $[8,9]$, while the high consumption of vegetables, fruits, and fish has provided a protective effect [9-11].

As with dietary patterns, studies on isolated nutrients have also demonstrated an influence in the development of MS, thus highlighting the importance of an adequate diet in terms of both macro- and micronutrients. Saturated fat intake greater than $10 \%$ of the total caloric value indicated a risk for MS in Brazilian adults [11]. Low intake of antioxidant nutrients such as vitamin $C$, selenium, and zinc might also predispose the development of MS [12,13]. Negative significant correlation coefficients were observed among dietary fat, energy, protein intake, and serum antioxidant state. It is well known that oxidative stress plays a role in the pathogenesis of MS components [12].

Deficiency of 25(OH)D has been linked to both the etiology of MS and the isolated components [14]. A metaregression model showed that dietary magnesium intake is significantly and inversely associated with the risk of metabolic syndrome. These findings are consistent with clinical studies that demonstrated that magnesium oral supplementation improved metabolic profile and blood pressure in metabolically obese, normal-weight individuals $[15,16]$.

National dietary surveys performed in the Brazilian adult population have found unbalanced diet in proportion to intake of energy and macronutrients such as lowcarbohydrate and high-fat diet. In addition, the intake of calcium, vitamin $\mathrm{D}$, and vitamin $\mathrm{E}$ was inadequate in more than $80 \%$ of both men and women $[17,18]$. However, studies using statistical methods for known deficiency of nutrient intakes in patients with MS are still scarce in the literature.

Hence, the present study aimed to assess the habitual nutrient intakes of patients with MS. The identification of possible dietary inadequacies will be useful for health care professionals to prevent and treat this disease.

\section{Methods}

\section{Study design}

This analytical, cross-sectional study was conducted at the Hospital Universitario Onofre Lopes (HUOL), located in Natal, RN, Northeast Brazil. This study was approved by the hospital's Research Ethics Committee under protocol number CAAE no. 13699913.7.0000.5292. All participants signed an informed consent form.

\section{Population and the study cohort}

The population of the study consisted of adults and elderly adults of both sexes seen at the endocrinology outpatient clinic of the HUOL.

The inclusion criteria were age 19-80 years and the presence of MS according to the criteria of the National Cholesterol Education Program-Third Adult Treatment Panel (NCEP-ATP III) [1]. The cut-off point used by the study for fasting glucose was $100 \mathrm{mg} / \mathrm{dL}$. The diagnosis of MS was based on the presence of at least three of the following: waist circumference $>102 \mathrm{~cm}$ in men and $>88 \mathrm{~cm}$ in women; triglyceride level $\geq 150 \mathrm{mg} / \mathrm{dL}$; HDL-c level $<40 \mathrm{mg} / \mathrm{dL}$ in men and $<50 \mathrm{mg} / \mathrm{dL}$ in women; systolic blood pressure $\geq 130 \mathrm{mmHg}$ and/or diastolic blood pressure $\geq 85 \mathrm{mmHg}$ or use of antihypertensive drugs; and fasting glucose $\geq 100 \mathrm{mg} / \mathrm{dL}$ or use of oral antidiabetic drugs.

The exclusion criteria were type 1 diabetes mellitus; type 2 diabetes mellitus with insulin use; use of glucocorticoids in the past 3 months; use of calcium or vitamin $\mathrm{D}$ supplements in the past 30 days; and use of anticonvulsants or rifampicin. Pregnant and nursing patients and patients with kidney failure were also excluded.

Between June 2013 and May 2014, 1500 medical records were screened. A total of 140 individuals met the inclusion criteria, 714 had one or more exclusion criteria, and 646 did not have a diagnosis of MS. Of the 140 eligible patients, 103 were finally included in the study, representing a sample loss of $26 \%$.

First, we collected the anthropometric measurements of the patients and administered the 24-h recall (24-HR) and a questionnaire on lifestyle and health status. We then conducted biochemical tests and scheduled a second administration of the 24-HR after 30-45 days.

\section{Anthropometric assessment}

The body mass index (BMI) of adults ( $<60$ years) was classified according to the recommendations of the World Health Organization (WHO) [19]. The BMI of elderly participants (i.e. $\geq 60$ years) was classified according to the criteria given by Lipschitz [20].

Waist circumference was measured at the midpoint between the last rib and the iliac crest by using an inelastic tape measure. Waist circumference was considered elevated when it was $>88 \mathrm{~cm}$ in women and $>102 \mathrm{~cm}$ in men [1].

\section{Blood pressure}

Blood pressure was measured as recommended by the VI Brazilian guidelines on hypertension [21]. High blood pressure was defined as systolic blood pressure $\geq 130 \mathrm{mmHg}$ and/or diastolic blood pressure $\geq 85 \mathrm{mmHg}$. 


\section{Biochemical tests}

Blood samples were collected via venipuncture after an overnight fast of 10-12 h. Blood glucose, triglycerides, and HDL-c levels were determined via colorimetry by using automatic equipment and kits from Wiener ${ }^{\circledR}$ lab 2000 (Rosario, Argentina).

\section{Lifestyle assessment}

Alcohol intake was classified according to the type of alcoholic beverage and the number of servings consumed in a month. A serving was defined as a can of beer; a glass of wine; or a shot of rum, vodka, whisky, or any other distilled beverage [22].

The smoking status was classified as follows: nonsmoker, when the individual had smoked fewer than 100 cigarettes over his lifetime; ex-smoker, when the individual had smoked at least 100 cigarettes over his lifetime but had not smoked in the past year; and smoker, when the individual had smoked more than 100 cigarettes over his lifetime and continued to smoke [23].

Physical activity was measured by using the International Physical Activity Questionnaire-short form (IPAQ-SF), validated for Brazil by Matsudo et al. [24]. Individuals were classified as inactive, irregularly active (categories A and B), active, and very active.

\section{Food intake assessment}

Habitual food intake was investigated by using two 24-HR at the following times: (1) every alternate day, except weekends and holidays to avoid collecting atypical data; and (2) distinctive times throughout the month, considering the family's purchasing power.

Photographs of utensils and containers were used to identify the food-serving items and quantify serving sizes, classified as small, average, or large. The foods were converted into nutrients by the software Virtual Nutri Plus ${ }^{\circledR} 2.0$ (São Paulo, Brazil). New preparations and foods were added to the database as necessary, along with their nutritional composition, from The Brazilian food composition table [25] and the United States Department of Agriculture (USDA) [26] database, whichever was more appropriate. Nutritional information collected from processed food labels was also included. Participants with reported energy intakes $<500$ or $>5000 \mathrm{kcal}$ were excluded [27]. Energy, macronutrient, and fiber intake adequacies were classified as recommended by the I Brazilian guidelines for diagnosing and treating metabolic syndrome [5].

The prevalence of inadequate micronutrients intake was estimated according to sex and age by using the estimated average requirements (EAR) cut-point method [28-31], except for iron, whose prevalence was calculated via the probability approach [32]. The prevalence of inadequate intake of each micronutrient was estimated considering the proportion of individuals with intake below the EAR value. Potassium intake was evaluated based on adequate intake (AI). The percentage of individuals whose sodium intake exceeded the tolerable upper intake level (UL) was also calculated [33].

\section{Statistical analysis}

Student's $t$ test was used to compare the dietary variables, expressed as means and standard deviations. The significance level was set at $5 \%$. The Kolmogorov-Smirnov test was used to verify data distribution symmetry. Nutrients with asymmetric distribution were converted into natural logarithms and retested for symmetry. After the logarithmic transformation, only vitamin B12 intake remained asymmetrically distributed, so it was excluded from the analysis. Continuous variables with symmetric distribution were expressed as means and standard deviations; variables with asymmetric distribution, as median and interquartile ranges $\left(\mathrm{Q}_{25}-\mathrm{Q}_{75}\right)$; and categorical variables, as absolute and relative frequencies.

Because of dietary data variability, intrapersonal variability was adjusted by the method developed by Nusser et al. [34]. Later, the results were adjusted for energy [35].

One-way analysis of variance (ANOVA) was used to determine intrapersonal variability, and estimates of intra- and interpersonal variances were based on the resulting quadratic means [34]. In order to control the confounding factors inherent to total energy intake and remove external variables, the data were adjusted for energy by using the residue method [35]. Energy was included as an independent variable, and absolute nutrient intake, as a dependent variable.

\section{Results}

The most frequent MS components were high blood pressure (78 \%), waist circumference (75\%), and altered fasting blood glucose (73\%). Characteristics of patients with MS are shown in Table 1. Mean patient age was $50 \pm 13.2$ years, and $82 \%(n=84)$ were women. Participants' lifestyles revealed that most did not consume alcoholic beverages, did not smoke and were active.

The mean energy intake of the cohort was $1523.1 \pm 592.2 \mathrm{kcal} / \mathrm{d}$, differing significantly between men $(1884.0 \mathrm{kcal} / \mathrm{d})$ and women $(1441.5 \mathrm{kcal} / \mathrm{d})$ $(p=0.003)$. Both men and women had a proper percentage of carbohydrate and fat intake, but a high percentage of protein intake (Table 2).

Men consumed more carbohydrates and proteins (crude values) (260.5 vs. $196.5 \mathrm{~g} / \mathrm{d}$ in women; $p=0.001$ and 89.2 vs. $63.9 \mathrm{~g} / \mathrm{d}$ in women; $p=0.016$, respectively), but women consumed more total fat (adjusted value) ( 47.6 vs. $41.3 \mathrm{~g} / \mathrm{d}$ in men; $p=0.007$ ). Although men 
Table 1 General characteristics of patients with metabolic syndrome by sex

\begin{tabular}{|c|c|c|c|}
\hline Variables & Total $(n=103)$ & Women $(n=84)$ & Men $(n=19)$ \\
\hline Age $\left(\right.$ years) ${ }^{a}$ & $50(13.2)$ & $49(13.4)$ & $57(10.4)$ \\
\hline Body mass index $\left(\mathrm{kg} / \mathrm{m}^{2}\right)^{\mathrm{a}}$ & $33.5(7.3)$ & $34.2(7.5)$ & $30.5(5.6)$ \\
\hline Waist circumference $(\mathrm{cm})^{\mathrm{a}}$ & $106.7(13.6)$ & $106.9(13.6)$ & $105.9(14.0)$ \\
\hline $\mathrm{HDL}$-cholesterol $(\mathrm{mg} / \mathrm{dL})^{\mathrm{a}}$ & $40.4(12.9)$ & $41.0(13.8)$ & $37.6(7.7)$ \\
\hline Systolic blood pressure $(\mathrm{mm} / \mathrm{Hg})^{\mathrm{a}}$ & $131.1(10.4)$ & $131.4(10.6)$ & $129.8(9.2)$ \\
\hline Diastolic blood pressure $(\mathrm{mm} / \mathrm{Hg})^{b}$ & $85.0(80.0-90.0)$ & $85.0(80.0-90.0)$ & $85.0(80.0-90.0)$ \\
\hline Triglycerides $(\mathrm{mg} / \mathrm{dL})^{\mathrm{b}}$ & $162.0(119.0-244.0)$ & $162.5(130.0-272.5)$ & $162.0(100.0-191.0)$ \\
\hline Fasting blood glucose $(\mathrm{mg} / \mathrm{dL})^{\mathrm{b}}$ & $109.0(102.0-136.0)$ & $109.0(102.0-131.8)$ & $109.0(104.0-163.0)$ \\
\hline \multicolumn{4}{|l|}{ Smoking status (\%) } \\
\hline Non-smoker & 50 & 51 & 42 \\
\hline Ex-smoker & 40 & 38 & 47 \\
\hline Smoker & 10 & 11 & 11 \\
\hline \multicolumn{4}{|l|}{ Alcohol intake (\%) } \\
\hline No intake & 81 & 86 & 63 \\
\hline $1-4$ servings/month & 6 & 5 & 11 \\
\hline$>4$ servings/month & 13 & 9 & 26 \\
\hline \multicolumn{4}{|l|}{ Level of physical activity (\%) } \\
\hline Inactive & 5 & 5 & 5 \\
\hline Irregularly active & 37 & 36 & 42 \\
\hline Active & 58 & 59 & 53 \\
\hline
\end{tabular}

a Results expressed as mean (standard deviation)

b Median $\left(\mathrm{Q}_{25}\right.$ and $\left.\mathrm{Q}_{75}\right)$ or \%

consumed more fiber (crude value) (18.8 vs. $13.3 \mathrm{~g} / \mathrm{d}$ in women; $p=0.011$ ), both men and women had inadequate fiber intake (Table 2).

The prevalence of inadequate vitamin $\mathrm{D}$, magnesium, and calcium intakes was high, ranging from 68 to $100 \%$ in both men and women (Tables 3 and 4). Additionally, men had a high prevalence of inadequate riboflavin (52.2\%), vitamin E (60.3\%), and zinc (75.5\%) intakes (Table 4). Approximately $35 \%$ of women had inadequate zinc intake.

The prevalence of inadequate vitamin $\mathrm{A}$, vitamin $\mathrm{C}$, thiamin, vitamin $B_{6}$, copper, and selenium intakes in men and women was below $50 \%$. None of the men had an inadequate iron intake. The potassium intake of all patients was below the AI (Tables 3 and 4). The mean sodium intake was high $(1964.6 \mathrm{mg} / \mathrm{d} \pm 520.3$ in women

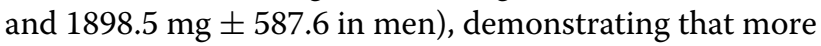
than $70 \%$ of the cohort exceeded the UL.

\section{Discussion}

An initial therapeutic approach to the prevention and treatment of MS involves lifestyle changes. The satisfactory results of the participants' lifestyles may stem from the fact that these patients were seen and/or followed at a multidisciplinary outpatient clinic, which may have encouraged the adoption of healthier lifestyles.
However, the findings of the food intake assessment suggest that, for most of the nutrients analyzed, patients with MS are exposed to the dietary risks due to the many inadequacies in terms of consumption of macro- and micronutrients.

The mean energy intake of the patients in the present cohort was lower than that found by another study of adult Brazilians [17], and the percentage macronutrient intake was similar to those of healthy individuals from Northeast Brazil $[11,36]$. The mean percentage protein intake exceeded the recommended level in both men and women. A high protein intake may affect kidney function, changing the glomerular filtration rate; moreover, since MS per se affects kidney function, we detected inadequate micronutrient intake that should be addressed in the clinical follow-up of these patients [37, 38].

Among dietary factors, dietary fiber intake could play an interesting role in the management of MS. In Brazil, fiber intake was found to be insufficient according to the 2008-2009 Household Budget Survey carried out to estimate the household availability of fiber [39]. Despite methodological differences, mean intake of dietary fiber in the current study of $14.3 \mathrm{~g} /$ day was similar to the $14.7 \mathrm{~g} /$ day reported in a survey conducted in northeast Brazil [39]. This suggests that current fiber intake in Brazil is inadequate: this is a cause for concern, since this 
Table 2 Energy and macronutrient intakes of patients with metabolic syndrome by sex

\begin{tabular}{|c|c|c|c|c|}
\hline $\begin{array}{l}\text { Energy/macronu- } \\
\text { trients/fiber }\end{array}$ & Total (103) & Women (84) & Men (19) & $p$ \\
\hline Energy (kcal/d) & $1523.1(592.2)$ & $1441.5(539.2)$ & $1884.0(691.8)$ & 0.003 \\
\hline \multicolumn{5}{|l|}{ Crude carbohydrate } \\
\hline $\mathrm{kcal} / \mathrm{d}$ & $833.3(317.9)$ & $786.1(295.2)$ & $1041.8(338.5)$ & \multirow[t]{3}{*}{0.001} \\
\hline$g / d$ & $208.3(79.5)$ & $196.5(73.8)$ & $260.5(84.6)$ & \\
\hline$\%$ of total calories & 55 & 55 & 56 & \\
\hline \multicolumn{5}{|c|}{ Adjusted carbohydrate } \\
\hline $\mathrm{kcal} / \mathrm{d}$ & $836.2(126.4)$ & $832.4(133.6)$ & $853.1(88.7)$ & \multirow[t]{3}{*}{0.412} \\
\hline$g / d$ & $209.1(31.6)$ & $208.1(33.4)$ & $213.3(22.2)$ & \\
\hline$\%$ of total calories & 55 & 54 & 56 & \\
\hline \multicolumn{5}{|l|}{ Crude protein } \\
\hline $\mathrm{kcal} / \mathrm{d}$ & $274.1(127.4)$ & $255.4(111.7)$ & $356.7(159.9)$ & \multirow[t]{3}{*}{0.016} \\
\hline$g / d$ & 68.5 (31.9) & $63.9(27.9)$ & $89.2(40.0)$ & \\
\hline$\%$ of total calories & 18 & 18 & 19 & \\
\hline \multicolumn{5}{|l|}{ Adjusted protein } \\
\hline $\mathrm{kcal} / \mathrm{d}$ & $275.2(54.1)$ & $272.3(50.6)$ & $288.3(67.4)$ & \multirow[t]{3}{*}{0.339} \\
\hline$g / d$ & $68.8(13.5)$ & $68.1(12.7)$ & $72.1(16.9)$ & \\
\hline$\%$ of total calories & 18 & 18 & 19 & \\
\hline \multicolumn{5}{|l|}{ Crude total fat } \\
\hline $\mathrm{kcal} / \mathrm{d}$ & $415.7(227.9)$ & $399.9(218.7)$ & $485.5(260.1)$ & \multirow[t]{3}{*}{0.140} \\
\hline$g / d$ & $46.2(25.3)$ & $44.4(24.3)$ & $54.0(28.9)$ & \\
\hline$\%$ of total calories & 27 & 27 & 25 & \\
\hline \multicolumn{5}{|l|}{ Adjusted total fat } \\
\hline $\mathrm{kcal} / \mathrm{d}$ & $417.8(83.2)$ & $428.2(78.7)$ & $371.9(89.0)$ & \multirow[t]{3}{*}{0.007} \\
\hline$g / d$ & $46.4(9.2)$ & $47.6(8.7)$ & $41.3(9.9)$ & \\
\hline$\%$ of total calories & 27 & 28 & 25 & \\
\hline \multicolumn{5}{|l|}{ Crude fiber } \\
\hline$g / d$ & $14.3(8.5)$ & $13.3(7.5)$ & $18.8(11.2)$ & 0.011 \\
\hline \multicolumn{5}{|l|}{ Adjusted fiber } \\
\hline$g / d$ & $12.7(3.8)$ & $12.6(3.7)$ & $13.2(4.7)$ & 0.614 \\
\hline
\end{tabular}

Results expressed as mean (standard deviation). The crude values refer to the absolute intakes of the study patients, and the adjusted values refer to the results after adjusting for intrapersonal variability [25] and energy [26]

Reference values according to the I Brazilian Guideline for Diagnosing and Treating Metabolic Syndrome, 2005

Carbohydrate: $50-60 \%$ of total energy intake

Protein: $15 \%$ of total energy intake

Total fat: $25-35 \%$ of total energy intake

Fiber: $20-30 \mathrm{~g} / \mathrm{d}$

nutrient plays a preventive role against several chronic diseases.

Inadequate fiber intake may hinder regulation of body weight, worsen dyslipidemia, and increase blood pressure and insulin resistance, consequently aggravating MS components [40]. The intestinal microbiota is an important factor in the development of obesity and metabolic disorders because of its interactions with the environment (e.g. diet) and/or genetic factors. Hence, dietary strategies to manipulate the intestinal microbiota, such as the use of probiotics and prebiotics, have been proposed as a treatment for obesity and a control for MS [41].

The prevalence of inadequate vitamin $\mathrm{D}$, calcium, and magnesium intakes found by the present study is corroborated by other robust Brazilian studies $[17,36]$. The results are worrisome, since patients with MS exhibit inadequate intake of nutrients involved in regulatory and antioxidant mechanisms of action, in conjunction with metabolic risks such as high blood pressure [42] and changes in fasting and postprandial blood glucose levels [43]. In adults, deficiency of 25(OH)D has been negatively linked to traditional MS components, such as waist circumference and triglyceride levels, and nontraditional components, such as fasting insulin levels [14]. Two of these components were among the most frequent in our study population, and, given that vitamin D is a modifiable factor in the nutritional treatment of MS, once vitamin D dietary deficiency is detected, it becomes an important variable of nutritional status.

In addition to the role played in bone metabolism, dietary calcium has been linked to a lower risk of developing MS, as it takes part in the regulatory mechanisms of obesity, hypertension, dyslipidemia, and insulin resistance. The adequate intake of calcium, prioritizing the consumption of low-fat dairy products (except cheese), has been positively associated with a decreased incidence of MS, glucose intolerance, and diabetes mellitus type2 [44].

A low dietary magnesium intake has also been associated with risk factors for MS, such as high fasting blood glucose levels, waist circumference, and triglyceride levels [45]. Sang-Yhun et al. [15], based on a meta-regression model of observational studies, showed a statistically significant inverse association between dietary magnesium intake and risk of MS, with an overall estimate of a $12 \%$ reduction in the risk of MS per each $150 \mathrm{mg} /$ day incremental increase in magnesium intake. This fact may be related to magnesium's role in glucose and lipid metabolism and blood pressure [46], justifying the importance of adequate magnesium intake.

Some pathophysiological mechanisms of MS arise from the imbalance between the formation and the inactivation of reactive oxygen species [47]. Therefore, the adequate dietary ingestion of antioxidant micronutrients such as vitamins $\mathrm{A}, \mathrm{C}$ and $\mathrm{E}$, selenium and zinc minerals, may be a protective factor to prevent tissue damage arising from oxidative stress $[12,13]$. Puchau et al. showed that the dietary total antioxidant capacity may provide an estimation of the risk of development of MS components [48]. However, findings regarding the association between antioxidant intake and the development of MS remain inconsistent. Wei et al. [13] and Motamed et al. [49] did not observe a significant association between 
Table 3 Nutritional recommendations, intake, and prevalence of inadequate micronutrient intakes in women with metabolic syndrome $(n=84)$

\begin{tabular}{|c|c|c|c|c|c|c|c|c|c|}
\hline \multirow[t]{2}{*}{ Micronutrients } & \multirow[t]{2}{*}{ EAR/AI } & \multirow[t]{2}{*}{ Mean } & \multirow[t]{2}{*}{ SD } & \multicolumn{5}{|c|}{ Intake percentiles } & \multirow[t]{2}{*}{$\%$ of inadequacy } \\
\hline & & & & 10 th & 25 th & 50th & 75th & 90th & \\
\hline Vitamin A $(\mu \mathrm{g} / \mathrm{d})^{\mathrm{a}}$ & 500 & 659.8 & 518.9 & 263.4 & 354.8 & 498.4 & 760.2 & 1427.9 & 37.8 \\
\hline Vitamin C (mg/d) & 60 & 88.5 & 83.3 & 27.0 & 38.9 & 73.2 & 109.3 & 163.1 & 36.7 \\
\hline Vitamin D ( $\mu \mathrm{g} / \mathrm{d})$ & 10 & 2.7 & 1.3 & 1.3 & 1.7 & 2.4 & 3.1 & 4.6 & 100.0 \\
\hline Vitamin E (mg/d) $)^{b}$ & 12 & 12.1 & 6.1 & 5.6 & 7.5 & 10.9 & 15.7 & 21.0 & 49.2 \\
\hline Thiamin (mg/d) & 0.9 & 1.1 & 0.6 & 0.6 & 0.8 & 1.0 & 1.2 & 1.4 & 37.8 \\
\hline Riboflavin (mg/d) & 0.9 & 1.0 & 0.4 & 0.6 & 0.7 & 0.9 & 1.1 & 1.3 & 45.2 \\
\hline Vitamin B6 $(\mathrm{mg} / \mathrm{d})^{c}$ 19-50 years & 1.1 & 1.4 & 0.3 & 1.1 & 1.3 & 1.4 & 1.6 & 1.8 & 11.1 \\
\hline$>50$ years & 1.3 & 1.5 & 0.2 & 1.3 & 1.4 & 1.5 & 1.6 & 1.7 & 15.4 \\
\hline $\operatorname{Niacin}(\mathrm{mg} / \mathrm{d})^{\mathrm{d}}$ & 11 & 17.7 & 6.7 & 11.8 & 13.9 & 16.7 & 21.0 & 24.9 & 15.9 \\
\hline Phosphorus (mg/d) & 580 & 776.7 & 232.5 & 528.2 & 632.6 & 757.8 & 939.5 & 1060.2 & 19.8 \\
\hline Magnesium $(\mathrm{mg} / \mathrm{d})^{\mathrm{e}} 19-30$ years & 255 & 200.9 & 114.8 & 120.4 & 138.5 & 163.6 & 244.4 & 431.4 & 68.1 \\
\hline$>30$ years & 265 & 184.1 & 51.7 & 123.2 & 154.6 & 177.6 & 206.9 & 237.2 & 94.1 \\
\hline Zinc (mg/d) & 6.8 & 7.8 & 2.4 & 5.3 & 6.2 & 7.2 & 8.8 & 10.8 & 34.8 \\
\hline Copper (mg/d) & 0.7 & 0.9 & 0.3 & 0.7 & 0.7 & 0.8 & 0.9 & 1.1 & 25.5 \\
\hline Iron $(\mathrm{mg} / \mathrm{d})^{\mathrm{c}, \mathrm{f}} 19-50$ years & 8.1 & 11.4 & 2.3 & 9.0 & 10.3 & 10.8 & 12.7 & 13.7 & 2.0 \\
\hline$>50$ years & 5.0 & 11.2 & 1.1 & 10.0 & 10.2 & 11.0 & 11.9 & 12.9 & 7.8 \\
\hline Selenium ( $\mu \mathrm{g} / \mathrm{d})$ & 45 & 54.2 & 28.4 & 22.9 & 35.8 & 50.4 & 66.8 & 85.5 & 37.1 \\
\hline Calcium $(\mathrm{mg} / \mathrm{d})^{\mathrm{C}} 19-50$ years & 800 & 454.3 & 141.8 & 289.5 & 342.3 & 430.2 & 528.1 & 659.2 & 99.3 \\
\hline$>50$ years & 1000 & 463.3 & 111.7 & 330.5 & 373.3 & 456.0 & 542.9 & 607.3 & 100.0 \\
\hline Potassium $(\mathrm{mg} / \mathrm{d})^{g}$ & 4700 & 1706.1 & 514.0 & 1110.1 & 1374.5 & 1647.0 & 1945.0 & 2464.3 & - \\
\hline
\end{tabular}

EAR estimated average requirement; $A$ l adequate intake

a Calculated as retinol activity equivalents

b Calculated as a-tocopherol equivalents

c $19-50$ years $(n=44) ;>50$ years $(n=40)$

$d$ Calculated as niacin equivalents

e 19-30 years $(n=6)$; $>30$ years $(n=78)$

f Inadequate iron intake was calculated by the probability approach

9 Al value

the intake of vitamins $\mathrm{A}$ and $\mathrm{E}$ and the development of MS.

Inadequate intake of less than $50 \%$ was also observed for B-complex vitamins-thiamine, pyridoxine and niacin-in both men and women, with the exception of riboflavin, which showed an inadequate intake of $53 \%$ in men. A study on dietary pattern conducted in Chinese adults showed that the vitamin B group has a potentially beneficial effect in preventing MS [7]. These results prompt new discussions on the function of water-soluble vitamins in the pathophysiological mechanisms of chronic diseases.

Both men and women had inadequate zinc and selenium intakes. Therefore, zinc deficiency may induce abnormal insulin metabolism and oxidative stress. Besides that, zinc deficiency increases peripheral insulin resistance, central obesity, blood pressure, and triglyceride levels, and decreases HDL-c levels, all components that characterize MS [50]. As an antioxidant, selenium protects against the damage caused by oxidative stress because of the functions of selenoproteins. In an adult population, the dietary intake of selenium showed moderate association with MS in the second quartile of distribution [13]. Plasma selenium levels were correlated positively with all the components of MS in Lebanese adults [51].

Our study showed that the UL of sodium intake was exceeded in both men and women. This is worrisome, and, despite the inability to make inferences regarding exposure and outcomes in our study, we observed that $78 \%$ of patients had high blood pressure, one of the most frequent components of MS. The Korea National Health and Nutrition Examination Survey (KNHANES) demonstrated that sodium excretion is positively associated with MS components such as blood pressure, waist circumference, and triglyceride and fasting glucose levels were negatively associated with HDL-c levels [52]. On the other hand, the potassium intake was below the AI. 
Table 4 Nutritional recommendations, intake, and prevalence of inadequate micronutrient intakes in men with metabolic syndrome $(n=19)$

\begin{tabular}{|c|c|c|c|c|c|c|c|c|c|}
\hline \multirow[t]{2}{*}{ Micronutrients } & \multirow[t]{2}{*}{ EAR/AI } & \multirow[t]{2}{*}{ Mean } & \multirow[t]{2}{*}{ SD } & \multicolumn{5}{|c|}{ Intake percentiles } & \multirow[t]{2}{*}{$\%$ of inadequacy } \\
\hline & & & & 10th & 25 th & 50 th & 75th & 90th & \\
\hline Vitamin A $(\mu \mathrm{g} / \mathrm{d})^{\mathrm{a}}$ & 625 & 652.2 & 547.7 & 266.8 & 352.6 & 467.7 & 756.9 & 1287.3 & 48.0 \\
\hline Vitamin C (mg/d) & 75 & 99.8 & 78.7 & 29.6 & 58.7 & 86.6 & 118.4 & 151.5 & 37.8 \\
\hline Vitamin D $(\mu \mathrm{g} / \mathrm{d})$ & 10 & 2.6 & 1.4 & 1.2 & 1.6 & 2.3 & 3.1 & 4.7 & 100.0 \\
\hline Vitamin E (mg/d) $)^{b}$ & 12 & 10.6 & 5.1 & 4.4 & 7.2 & 9.9 & 14.1 & 16.9 & 60.3 \\
\hline Thiamin (mg/d) & 1 & 1.3 & 0.8 & 0.7 & 0.9 & 1.0 & 1.3 & 1.6 & 33.7 \\
\hline Riboflavin (mg/d) & 1.1 & 1.1 & 0.5 & 0.8 & 0.8 & 0.9 & 1.1 & 1.4 & 52.8 \\
\hline Vitamin B6 $(\mathrm{mg} / \mathrm{d})^{\mathrm{C}} 19-50$ years & 1.1 & 1.5 & 0.3 & 1.1 & 1.2 & 1.4 & 1.7 & 1.8 & 9.7 \\
\hline$>50$ years & 1.4 & 1.6 & 0.5 & 1.1 & 1.3 & 1.5 & 1.8 & 2.6 & 32.3 \\
\hline $\operatorname{Niacin}(\mathrm{mg} / \mathrm{d})^{\mathrm{d}}$ & 12 & 21.2 & 10.9 & 10.7 & 14.5 & 18.4 & 24.3 & 36.8 & 19.8 \\
\hline Phosphorus (mg/d) & 580 & 852.5 & 229.3 & 577.5 & 687.1 & 829.2 & 963.1 & 1128.9 & 11.7 \\
\hline Magnesium $(\mathrm{mg} / \mathrm{d})^{\mathrm{e}}$ 19-30 years & 330 & 168.2 & 36.1 & 114.1 & 144.4 & 162.3 & 203.9 & 216.1 & 100.0 \\
\hline$>30$ years & 350 & 220.7 & 68.8 & 135.4 & 170.1 & 202.3 & 248.5 & 350.0 & 97.0 \\
\hline Zinc (mg/d) & 9.4 & 7.3 & 3.1 & 4.4 & 5.3 & 6.7 & 8.1 & 10.4 & 75.5 \\
\hline Copper (mg/d) & 0.7 & 0.9 & 0.3 & 0.7 & 0.7 & 0.8 & 1.0 & 1.2 & 23.0 \\
\hline $\operatorname{Iron}(\mathrm{mg} / \mathrm{d})^{\mathrm{f}}$ & 6 & 11.7 & 2.5 & 9.1 & 10.6 & 11.3 & 12.8 & 16.1 & 0.0 \\
\hline Selenium ( $\mu \mathrm{g} / \mathrm{d})$ & 45 & 59.8 & 22.4 & 30.5 & 40.8 & 61.5 & 75.1 & 95.6 & 25.5 \\
\hline Calcium $(\mathrm{mg} / \mathrm{d})^{\mathrm{g}} 19-50$ years & 800 & 466.0 & 123.6 & 314.6 & 346.2 & 450.5 & 558.7 & 669.4 & 99.7 \\
\hline$>50$ years & 1000 & 639.5 & - & - & - & - & - & - & - \\
\hline Potassium $(\mathrm{mg} / \mathrm{d})^{\mathrm{h}}$ & 4700 & 1817.9 & 503.8 & 1350.0 & 1473.2 & 1721.3 & 2058.9 & 2506.7 & - \\
\hline
\end{tabular}

EAR estimated average requirement; $A$ l adequate intake

a Calculated as retinol activity equivalents

b Calculated as a-tocopherol equivalents

c $19-50 \mathrm{y}(n=6) ;>50 \mathrm{y}(n=13)$

d Calculated as niacin equivalents

e $19-30$ y $(n=6) ;>30$ y $(n=13)$

${ }^{f}$ Inadequate iron intake was calculated by the probability approach

g $19-50$ y $(n=18) ;>50$ y $(n=1)$

h Al value

A high sodium intake combined with a low potassium intake increases peripheral vascular resistance, consequently increasing blood pressure [53].

One of the main limitations of the present study is the inherent complexity of food intake assessment. The evaluation of dietary intake is susceptible to random and systematic errors, although in the present study, the HRs were administered by trained nutritionists who took care to minimize errors while collecting and analyzing data. Moreover, the data obtained were subsequently adjusted based on energy and intra-individual variation. Another limitation is the choice of the IPAQ-SF to measure physical activity. The IPAQ-SF has become the most widely used physical activity questionnaire; however, it tends to overestimate the amount of physical activity [54]. In fact, there are currently no perfect gold standard criteria for measuring physical activity. In our study, this variable was important only for the characterization of the participants. Besides that, we used the IPAQ-SF version validated for the Brazilian population.

\section{Conclusions}

The patients with MS had high protein intake, low fiber intake, and high prevalence of inadequate vitamin D, magnesium, and calcium intakes, regardless of the sex. The markedly inadequate intake of various micronutrients may exacerbate complications of MS. These findings indicate the importance of nutritional guidance in the healthcare of individuals exposed to the risks of MS and diabetes mellitus.

\section{Abbreviations}

MS: metabolic syndrome; HDL-c: high-density lipoprotein cholesterol; 24-HR: 24-hour recall; BMI: body mass index; EAR: estimated average requirement; UL: tolerable upper intake level; Al: adequate intake; IPAQ-SF: international physical activity questionnaire-short form. 


\section{Authors' contributions}

LFCP, JGL, ATOC and HTP conceived the study and designed the protocol. ATOC, SCVCL, and CHS did the statistical analyses. ATOC and SLSA wrote the manuscript. Overall responsibility: ATOC, HTP, SLSA, CHS, KCMS, JGL, SCVCL, and LFCP. All authors read and approved the final manuscript.

\section{Author details}

1 Post-Graduate Program in Health Sciences, Federal University of Rio Grande do Norte, Av. General Cordeiro de Farias, s/no- Petrópolis, Natal, RN CEP: 59012-570, Brazil. ${ }^{2}$ Post-Graduate Program in Nutrition, Federal University of Rio Grande do Norte, Av. Sen. Salgado Filho 3000, Lagoa Nova, Campus Central, Natal, RN CEP: 59078-970, Brazil. ${ }^{3}$ Department of Nutrition, School of Public Health of University of São Paulo, Av. Doutor Arnaldo, 715, Sumaré, São Paulo, SP CEP: 01246904, Brazil. ${ }^{4}$ Department of Nutrition, Federal University of Rio Grande do Norte, Av. Sen. Salgado Filho 3000, Lagoa Nova, Campus Central, Natal, RN CEP: 59078-970, Brazil. ${ }^{5}$ Departamento de Medicina Clínica, Universidade Federal do Rio Grande do Norte, Av. Nilo Peçanha, 620, Petrópolis, Natal, RN CEP: 59010-180, Brazil.

\section{Acknowledgements}

This research was supported by the National Council for Scientific and Technological Development (Conselho Nacional de Desenvolvimento Científico e Tecnológico_CNPq, Brazil; Grant No. 471761/2013-3).

\section{Competing interests}

The authors declare that they have no competing interests.

Received: 18 November 2015 Accepted: 2 April 2016

Published online: 14 April 2016

\section{References}

1. National Cholesterol Education Program (NCEP) Expert panel on detection, evaluation, and treatment of high blood cholesterol in adults (adult treatment panel III): third report of the National Cholesterol Education Program (NCEP) expert panel on detection, evaluation, and treatment of high blood cholesterol in adults (adult treatment panel III) final report. Circulation 2002;106: 3143-3421.

2. Alberti KGMM, Eckel RH, Grundy SM, Zimmet PZ, Cleeman JI, Donato KA, et al. Harmonizing the metabolic syndrome: a joint interim statement of the International Diabetes Federation task force on epidemiology and prevention; national heart, lung, and blood institute; American Heart Association; World Heart Federation; International Atherosclerosis Society; and International Association for the Study of Obesity. Circulation. 2009;120:1640-5.

3. Vidigal FC, Bressan J, Babio N, Salas-Salvadó J. Prevalence of metabolic syndrome in Brazilian adults: a systematic review. BMC Publ Health. 2013;13:1198.

4. Vidigal FC, Ribeiro AQ, Babio N, Salas-Salvadó J, Bressan J. Prevalence of metabolic syndrome and pre-metabolic syndrome in health professionals: IATINMETS Brazil study. Diab Metab Syndr. 2015;7:6.

5. Brazilian I. Guideline for the diagnosis and treatment of metabolic syndrome. Arq Bras Cardiol. 2005;84:28.

6. Nava LT, Zambrano JM, Arviso KP, Brochetti D, Becker KL. Nutrition-based interventions to address metabolic syndrome in the Navajo: a systematic review. J Clin Nurs. 2015;24:3024-45.

7. Bian S, Gao Y, Zhang M, Wang X, Liu W, Zhang D, Huang G. Dietary nutrient intake and metabolic syndrome risk in Chinese adults: a case-control study. Nutr J. 2013;12:106.

8. Denova-Gutierrez E, Castanon S, Talavera JO, Gallegos-Carrillo K, Flores M, Dosamantes-Carrasco D, et al. Dietary patterns are associated with metabolic syndrome in an urban Mexican population J Nutr. 2010;140:1855-63.

9. Farhangi MA, Jahangiry L, Asghari-Jafarabadi M, Najafi M. Association between dietary patterns and metabolic syndrome in a sample of Tehranian adults. Obes Res Clin Pract. 2015. doi:10.1016/j.orcp.2015.05.011 (in press).
10. Kim J. Grains, vegetables, and fish dietary pattern is inversely associated with the risk of metabolic syndrome in South Korean adults. J Am Diet Assoc. 2011;111:1141-9.

11. Oliveira EP, MCLellan KC, de Silveira LVA, Burini RC. Dietary factors associated with metabolic syndrome in Brazilian adults. Nutr J. 2012;11:13.

12. Li Y, Guo H, Wu M, Liu M. Serum and dietary antioxidant status is associated with lower prevalence of the metabolic syndrome in a study in Shanghai, China. Asia Pac J Clin Nutr. 2013;22:60-8.

13. Wei J, Zeng C, Gong Q-y, Li X-x, Lei G-h, Yang T-b. Associations between dietary antioxidant intake and metabolic syndrome. PLoS One. 2015;10:e0130876.

14. Kayaniyil S, Vieth R, Harris SB, Retnakaran R, Knight JA, Gerstein HC, et al. Association of 25(OH)D and PTH with metabolic syndrome and its traditional and nontraditional components. J Clin Endocrinol Metab. 2011;96:168-75.

15. Sang-Yhun J, Whan-Seok C, Sun-Myeong O, Chul-Min K, Do-Hoon K. Dietary magnesium intake and metabolic syndrome in the adult population: dose-response meta-analysis and meta-regression. Nutrients. 2014;6:6005-19.

16. Rodríguez-Moran M, Guerrero-Romero F. Oral magnesium supplementation improves the metabolic profile of metabolically obese, normalweight individuals: a randomized double-blind placebo-controlled trial. Arch Med Res. 2014;45:388-93.

17. Araujo MC, Bezerra IN, Barbosa FS, Junger WL, Yokoo EM, Pereira RA. Macronutrient consumption and inadequate micronutrient intake in adults. Rev Saúde Pública. 2013;47:177-89.

18. Fisberg RM, Marchioni DML, Castro MA, Junior EV, Araújo MC, Bezerra IN. Inadequate nutrient intake among the Brazilian elderly: National Dietary Survey 2008-2009. Rev Saúde Pública. 2013;47:222-30.

19. World Health Organization. Obesity: preventing and managing the global epidemic. Report of a WHO Consultation. WHO Technical Report Series 894. Geneva: World Health Organization; 2000.

20. Lipschitz DA. Screening for nutritional status in the elderly. Prim Care. 1994;21:55-67.

21. VI Brazilian Guideline on Hypertension. Brazilian Society of Cardiology; Brazilian Society of Hypertension; Brazilian Society of Nephrology. Arq Bras Cardiol. 2009/2010;95:1-51.

22. Ministério da Saúde. Secretaria de Vigilância em Saúde. Departamento de Vigilância de Doenças e Agravos não Transmissíveis e Promoção da Saúde. Vigitel Brazil 2013. Vigilância de Fatores de Risco e Proteção para Doenças Crônicas por Inquérito Telefônico Brasília: Ministério da Saúde; 2014.

23. Brasil: Ministério da Saúde. Instituto Nacional de Câncer (INCA). Abordagem e tratamento do fumante: Consenso 2001. Rio de Janeiro: INCA; 2001. p. 38

24. Matsudo SM, Araújo TL, Matsudo VKR, Andrade DR, Andrade EL, Oliveira LC, et al. International physical activity questionnaire (IPAQ): study of validity and reliability in Brazil. Rev Bras Ativ Fis Saúde. 2001;6:5-18.

25. The Brazilian food composition table/NEPA_UNICAMP. 4th ed. rev. e ampl. Campinas: NEPA-UNICAMP; 2011. p. 161.

26. United States Department of Agriculture (USDA). Agricultural Research Service. USDA National nutrient database for standard reference, Release 25. [food composition table]. 2012.

27. Willett WC. Nutritional epidemiology. 2a ed. New York: Oxford University; 1998.

28. Institute of Medicine, Food and Nutrition Board. Standing Committee on the Scientific Evaluation of Dietary Reference Intakes. Dietary reference intakes: applications in dietary assessment. Washington: National Academy Press; 2000. p. 287.

29. Institute of Medicine, Food and Nutrition Board. Dietary reference intakes for thiamin, riboflavin, niacin, vitamin B6, folate, vitamin B12, pantothenic acid, biotin, and choline. Washington: National Academy Press; 1998. p. 564.

30. Institute of Medicine, Food and Nutrition Board. Dietary reference intakes for vitamin C, vitamin E, selenium, and carotenoids. Washington: National Academy Press; 2000. p. 506.

31. Institute of Medicine, Food and Nutrition Board. Dietary Reference Intakes for Calcium and Vitamin D. Washington: National Academy Press; 2011. p. 1115. 
32. Institute of Medicine. DRI's. Dietary reference intakes for vitamin A, vitamin $\mathrm{K}$, arsenic, boron, chromium, copper, iodine, iron, manganese, molybdenum, nickel, silicon, vanadium and zinc. Washington: National Academy Press; 2002. p. 773.

33. Institute of Medicine, Food and Nutrition Board (US). Dietary reference intakes for water, potassium, sodium, chloride, sulfate. Washington: National Academy Press; 2004. p. 617.

34. Nusser SM, Carriquiry AL, Dodd KW, Fuller WA. A semiparametric transformation approach to estimating usual daily intake distributions. J Am Stat Assoc. 1996;91:1440-9.

35. Willett WC, Stampfer MJ. Total energy intake: implications for epidemiological analyses. Am J Epidemiol. 1986;124:17-27.

36. Instituto Brasileiro de Geografia e Estatística (IBGE). Pesquisa de orçamentos familiares 2008-2009: análise do consumo alimentar pessoal no Brasil//BGE, Coordenação de Trabalho e Rendimento. Rio de Janeiro: IBGE; 2011. p. 150.

37. Juraschek SP, Appel $\sqcup$, Anderson CA, Miller ER. Effect of a high-protein diet on kidney function in healthy adults: results from the OmniHeart trial. Am J Kidney Dis. 2013;61:547-54.

38. Li Y, Xie D, Qin X, Tang G, Xing H, Li Z, et al. Metabolic syndrome, but not insulin resistance, is associated with an increased risk of renal function decline. Clin Nutr. 2015;34:269-75.

39. Sardinha AN, Canella DS, Martins APB, Claro RM, Levy RB. Dietary sources of fiber intake in Brazil. Appetite. 2014;79:134-8.

40. Galisteo M, Duarte J, Zarzuelo A. Effects of dietary fibers on disturbances clustered in the metabolic syndrome. J Nutr Biochem. 2008; 19:71-84

41. Kovatcheva-Datchary P, Arora T. Nutrition, the gut microbiome and the metabolic syndrome. Best Pract Res Clin Gastroenterol. 2013;27:59-72.

42. Peregrín CM, Rodríguez FL, del Castellano MMC. Vitamina D e hipertensión arterial. Med Clin (Barc). 2012;138:397-401.

43. Sales CH, Pedrosa LFC, Lima JG, Lemos TMAM, Colli C. Influence of magnesium status and magnesium intake on the blood glucose control in patients with type 2 diabetes. Clin Nutr. 2011;30:359-64.
44. Fumeron F, Lamri A, Abi KC, Jaziri R, Porchay-Balderelli I, Lantieri O, et al. Dairy consumption and the incidence of hyperglycemia and the metabolic syndrome: results from a French prospective study. data from the epidemiological study on the insulin resistance syndrome (DESIR). Diab Care. 2011;34:813-7.

45. Mirmiran P, Shab-Bidar S, Hosseini-Esfahani F, Asghari G, HosseinpourNiazi S, Azizi F. Magnesium intake and prevalence of metabolic syndrome in adults: Tehran Lipid and Glucose Study. Publ Health Nutr. 2012;15:693-701.

46. Champagne CM. Magnesium in hypertension, cardiovascular disease, metabolic syndrome, and other conditions: a review. Nutr Clin Pract. 2008;23:142-51.

47. Roberts CK, Sindhu KK. Oxidative stress and metabolic syndrome. Life Sci. 2009;84:705-12

48. Puchau B, Zule A, Echavarri A, Hermsdorff HHM, Martinez JA. Dietary total antioxidant capacity is negatively associated with some metabolic syndrome features in healthy young adults. Nutrition. 2010;26:534-41.

49. Motamed S, Ebrahim M, Safarian M, Ghayour-Mobarhan M, Mouhebati $M$, Azarpazhouh $M$, et al. Micronutrient intake and the presence of the metabolic syndrome. N Am J Med Sci. 2013;5:377-85.

50. Miao X, Sun W, Fu Y, Miao L, Cai L. Zinc homeostasis in the metabolic syndrome and diabetes. Front Med. 2013;7:31-52.

51. Obeid O, Elfakhani M, Hlais S, Iskandar M, Batal M, Mouneimne Y, et al. Plasma copper, zinc, and selenium levels and correlates with metabolic syndrome components of Lebanese adults. Bio Trace Elem Res. 2008;123:58-65.

52. Oh SW, Han KH, Han SY, Koo HS, Kim S, Chin HJ. Association of sodium excretion with metabolic syndrome, insulin resistance, and body fat. Medicine. 2015;94:1-7.

53. Perez V, Chang ET. Sodium-to-potassium ratio and blood pressure, hypertension, and related factors. Adv Nutr. 2014;5:712-41.

54. Lee PH, Macfarlane DJ, Lam TH, Stewart SM. Validity of the international physical activity questionnaire short form (IPAQ-SF): a systematic review. Int J Behav Nutr Phys Act. 2011;8:115.

\section{Submit your next manuscript to BioMed Central and we will help you at every step:}

- We accept pre-submission inquiries

- Our selector tool helps you to find the most relevant journal

- We provide round the clock customer support

- Convenient online submission

- Thorough peer review

- Inclusion in PubMed and all major indexing services

- Maximum visibility for your research

Submit your manuscript at www.biomedcentral.com/submit
() Biomed Central 